\section{PSQ-100 PUBLIC PERCEPTIONS AND CONCERNS INCLUDING MEDICATION AWARENESS IN LIFESTYLE HEALTH CAMPAIGNS}

${ }^{1} \mathrm{~F}$ Alhomoud*, ${ }^{2} \mathrm{~K}$ Alameer, ${ }^{2} \mathrm{Z}$ Almousa, ${ }^{2} \mathrm{M}$ Almatar, ${ }^{1} \mathrm{~W}$ Alzlaiq, ${ }^{1} \mathrm{~F}$ Alhomoud. ${ }^{1} \mathrm{Imam}$ Abdulrahman Bin Faisal University, Department of Pharmacy Practice- College of Clinical Pharmacy, Dammam, Saudi Arabia; ${ }^{2}$ Imam Abdulrahman Bin Faisal University, College of Clinical Pharmacy, Dammam, Saudi Arabia

\subsection{6/ejhpharm-2019-eahpconf.533}

Background The irrational use of medicines is likely to result in therapeutic failure, disease progression and the need for more aggressive treatments. ${ }^{1}$ One of the ways to alter such behaviour and increase public awareness about appropriate medication use is by designing and delivering a public health medicine awareness campaign.

Purpose This study aimed to evaluate the general public's awareness of medication use and public health campaigns.

Material and methods This was a cross-sectional survey study. Participants were aged 18 years or over and able to speak Arabic or English. An online survey (Ranjabar's questionnaire) ${ }^{2}$ was distributed from January to March 2017 to a random sample of 451 participants by email and social media via an internet link leading to a web-based survey platform in QuestionPro. Data were entered and analysed using the Statistical Package for the Social Sciences (SPSS) 22.

Results Three-hundred and forty-seven participants $(76 \%$ females, aged 18-85 years) were on a mean (SD) of two (1.86) regular medicines and 225 were on non-prescription medications. Seventy-one and 63 per cent of those surveyed consulted a doctor or a pharmacist, respectively, for advice about their medications. The participants were curious mainly about the side effects of treatment (79\%), followed by drug interactions and contraindications (55\%). Most participants agreed or strongly agreed that their medications were necessary to improve their condition (82\%), prevent the progress of their condition $(85 \%)$ and reduce the risk of complications (90\%). Seventy-seven per cent of participants reported seeing a public health campaign previously. TV (58\%) and Twitter $(55 \%)$ were reported as the most appropriate tools to help in delivering a good public health campaign. Ninety-one per cent believed that a public health campaign can increase people's awareness about their lifestyle and $73 \%$ declared that the use of medication should be part of a public health campaign.

Conclusion The findings are consistent with the literature which supports the need for a thorough medication awareness campaign. ${ }^{1}$

\section{REFERENCES AND/OR ACKNOWLEDGEMENTS}

1. Ranjbar M, Aslanpour Z, Kostrzewski A, Cooke AD. Public health campaigns and medicine use awareness: a systematic literature review. Health 2017:9:1689-710.

2. Ranjbar M [internet]. Public health campaign for medicine awareness. England: National Health Service (NHS) Health Research Authority (HRA), 2015.

No conflict of interest.

\section{PSQ-101 LESS-CHRON FOR DEPRESCRIBING IN NURSING HOME RESIDENTS}

${ }^{1} \mathrm{MC}$ Sánchez Argaiz, ${ }^{1} \mathrm{MR}$ Cantudo Cuenca, ${ }^{2} \mathrm{~S}$ Guijarro Herrera, ${ }^{3} \mathrm{R}$ Alvarez Sánchez* ${ }^{1}$ B Muñoz Cejudo. 'San Agustín Hospital, Hospital Pharmacy, Linares Jaén, Spain: ${ }^{2}$ Virgen de Las Nieves University Hospital, Hospital Pharmacy, Granada, Spain; ${ }^{3}$ Campus de La Salud Hospital, Hospital Pharmacy, Granada, Spain

10.1136/ejhpharm-2019-eahpconf.534
Background Patients with multimorbidity are an especially complex population. Multimorbidity is associated with poorer health outcomes and significant polypharmacy. These make patients more vulnerable to drug-related problems, causing a higher number of hospital admissions. This kind of population is common in nursing homes, and the withdrawal of medications might be an appropriate decision, resulting in significant clinical benefits. A review and evaluation process of long-term therapeutic plans aiming to stop, substitute or reduce the dosage of those drugs that under certain clinical conditions can be considered unnecessary or inappropriate, is necessary.

The List Evidence-baSed depreScribing for CHRONic patients criteria (LESS-CHRON) is a list of 27 drugs and specific clinical situations thatpresent an opportunity for deprescribing in patients with multimorbidity or similar situation (chronic, elderly with comorbidities, polymedicated).

Purpose The aim of this study was to review all the medical treatments and clinical situation of the institutionalised patients in nursing homes, using LESS-CHRON and analyse the pharmacist interventions.

Material and methods Cross-sectional study in June 2018. We included all the nursing home residents older than 65 years in a residential care centre linked to a hospital pharmacy. We reviewed, with the physician responsible, the pharmacological treatment and clinical situation of the residents to assess the benefits and risks of medication withdrawal, then we valued the acceptance.

Results We included 55 nursing home residents, 50\% males, mean age $82.5 \pm 9$ years. The mean drugs prescribed per patient was $8.5 \pm 4.4$. Seventy-three per cent of the residents had a Charlson comorbidity index $\geq 5$. We detected 39 inappropiate prescriptions by LESS-CHRON: 18\% (seven) digestive system drugs, 41\% (16) blood and cardiovascular system drugs, 5\% (two) genitourinary tract and 36\% (14) central nervous sytem. After the clinical review and evaluation process with the physician, the acceptance intervention rate to reduce dose or stop medication was $10(26 \%)$. However, of the 29 (74\%) inappropiate prescriptions without modifications in the treatment, 22 had a clinical explanation.

Conclusion LESS-CHRON is a suitable tool for clinical practice to select which patients can benefit from deprescribing and can avoid several adverse events related to drugs, but requires a good knowledge of the clinical history and work in common with physicians.

\section{REFERENCES AND/OR ACKNOWLEDGEMENTS}

No conflict of interest.

\section{PSQ-102 ANTIMICROBIAL TREATMENT INADEQUACY IN AN EMERGENCY DEPARTMENT}

${ }^{1} \mathrm{~F}$ Oltra Hostalet, ${ }^{2} \mathrm{M}$ Nuñez Nuñez, ${ }^{3} \mathrm{M}$ Moya-Martin, ${ }^{2}$ Ás Raquel ${ }^{*} .{ }^{1}$ Hospital Universitario Virgen Macarena, Ugc Urgencias, Seville, Spain; ${ }^{2}$ Hospital Universitario San Cecilio de Granada, Ugc Farmacia, Granada, Spain; ${ }^{3}$ Hospital Universitario Virgen Macarena, Pharmacy, Seville, Spain

\subsection{6/ejhpharm-2019-eahpconf.535}

Background The fast turnover of patients make the Emergency Department Observation Units (EDOU) a complex setting for antimicrobial stewardship interventions. To identify modifiable factors to improve inappropriate antimicrobial prescriptions (AT) can help in the design of targeted interventions. 